\title{
La contribución de las fórmulas existentes de cooperación intermunicipal en la equidad territorial: el caso de la Mancomunitat de la Ribera Alta
} The contribution of the existing formulas of
inter-municipal cooperation to territorial equity:
the Case of the Mancomunitat de la Ribera Alta

Joaquín Farinós Dasí ${ }^{1}$, Andrés Gomis Fons ${ }^{2}$

Resumen

La buena gobernanza está considerada, tanto desde el punto de vista político como geográfico y económico, como un elemento clave para la competitividad territorial y urbana. El artículo presenta un punto de vista crítico y alternativo a esta formulación, entendiendo la gobernanza como factor del objetivo de equilibrio territorial. Para ello, se consideran dos conceptos clave: policentrismo (no morfológico, sino funcional y urbanorural) y cooperación territorial (de geometrías variables), como forma más eficiente de dotar servicios y aplicar políticas con impacto territorial. Para todo ello se toman como referencia la idea de cohesión territorial, configurada principalmente desde la Unión Europea, y la Estrategia Territorial de la Comunitat Valenciana, que pone énfasis en los elementos de gestión territorial. Tras esta contextualización, el artículo presenta el análisis de la forma de cooperación intermunicipal predominante en el territorio valenciano, la mancomunidad, mediante un estudio de caso: la Mancomunitat de la Ribera Alta.

Palabras Clave: gobernanza; cooperación territorial; cohesión territorial; relaciones urbano-rurales; Comunitat Valenciana; Ribera Alta.

1 IIDL-Dpto.de Geografía, UVEG. Joaquin.Farinos@uv.es ORCID iD: http://orcid.org/00000002-1872-8556

2 Máster en Gestión y Promoción del Desarrollo Local (IIDL-UVEG).angofons@alumni.uv.es ORCID iD: http://orcid.org/0000-0001-7832-8872 


\begin{abstract}
Good governance is considered, both politically, geographically and economically, a key element for territorial and urban competitiveness. This article presents a critical and alternative point of view to this formulation, considering governance as a key factor of the objective of territorial balance. For this, two key concepts are considered: polycentrism (not morphological but functional and urban-rural) and territorial cooperation (of variable geometries) as the most efficient way to provide services and apply policies with territorial impact. The idea of territorial cohesion, as configured from the European Union, and the Territorial Strategy of the Comunitat Valenciana, which put emphasis on the key elements of territorial management, are taken as reference. After this contextualization, this paper presents the analysis of the predominant form of inter-city cooperation in the Valencian territory, the commonwealth, through a case study: the Mancomunitat de la Ribera Alta.
\end{abstract}

KEY WORDS: governance; territorial cooperation; territorial cohesion; urban-rural relations; Comunitat Valenciana; Ribera Alta.

Cómo citar este artículo/Citation: Farinós Dasí, Joaquín y Gomis Fons, Andrés (2017): "La contribución de las fórmulas existentes de cooperación intermunicipal en la equidad territorial: el caso de la Mancomunitat de la Ribera Alta", Estudios Geográficos, LXXVIII/283, pp. 465-491.

\title{
1. INTRODUCCIÓN
}

La cohesión territorial es un concepto desarrollado a partir de los documentos de política regional de la Unión Europea. Para lograr la cohesión territorial y el desarrollo equilibrado de los territorios (justicia espacial) se destaca el papel de la cooperación territorial, las nuevas formas de gobernanza y el policentrismo. La aproximación a estos conceptos puede hacerse desde diferentes perspectivas y escalas. En este artículo nos centramos en el ámbito de proximidad y, concretamente, en la incidencia que para la equidad en el territorio tienen las mancomunidades, mediante un estudio de caso en la comarca de la Ribera Alta. La coexistencia de ciudades intermedias que juegan el papel de núcleo urbano de cierta entidad, junto con municipios con poca población y dotación de servicios, es el principal elemento que, desde el punto de vista del desarrollo policéntrico y urbano-rural integrado, lo convierten en un caso de análisis apropiado para ilustrar este tipo de desarrollo.

El presente trabajo no pone el foco en las dinámicas y relaciones litoralinterior, como hicimos previamente en el caso del proyecto de Comarcas Centrales Valencianas (Farinós y Payà 2006), sino en el engranaje urbano-rural del sistema de ciudades medias, dada su importancia en la vertebración del 
territorio valenciano. En este caso se recupera y amplía hacia lo rural una idea en la que ya se insistía desde una perspectiva urbana décadas atrás: la importancia de las ciudades medias. Se trata de estudiar cómo contribuye la cooperación intermunicipal a mejorar el acceso ciudadano a los servicios de interés general. Partimos, como hipótesis, de la conveniencia de un desarrollo integrado en el que se complemente el nodo principal urbano con su entorno rural.

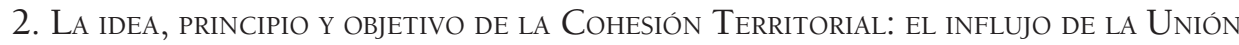
EUROPEA

El Tratado de la Unión Europea de 1991 (Tratado de Maastricht) hace referencia en su art. 3.3 al fomento de la «cohesión económica, social, cultural y territorial», y en desarrollo de este compromiso se articula la política de cohesión, un marco de solidaridad a escala europea para un desarrollo territorial equilibrado y sostenible. El Tratado de Funcionamiento de la Unión Europea - TFUE - se refiere en el Título XVIII a esta política, con la que se pretende reducir las diferencias entre los niveles de desarrollo de las regiones. Sin embargo, es con la Estrategia Territorial Europea -ETE- de 1999, el «Tercer Informe sobre la cohesión económica y Social» (CE 2004: 27) y el Tratado de Lisboa de 2007 cuando se reconoció progresivamente el concepto de cohesión territorial (vid. Farinós 2009 y 2013). Como destaca Faludi (2005: 16), ésta «pone el énfasis en las oportunidades de desarrollo para estimular la cooperación y la creación de redes, prestando más atención a las fortalezas de cada territorio y a una mayor adecuación de los instrumentos de las políticas». Como respuesta al desarrollo desequilibrado de la UE, en la ETE se apuesta por el policentrismo y la descentralización para la competitividad y equidad territorial en el conjunto de la UE, algo que continuará presente en las sucesivas agendas territoriales (2004, 2007 y 2011) con un método más intergubernamental y menos comunitario. En ello tendría una importancia capital la cooperación territorial, que pasa de iniciativa comunitaria (Interreg) a ser el tercero de los objetivos de la política de cohesión en el cuarto periodo de programación 2007-2014.

Este reconocimiento culminó en 2008 con la publicación del «Libro Verde sobre la cohesión territorial. Convertir la diversidad territorial en un punto fuerte» (CE 2008), donde se advierten los riesgos que implica la tendencia a la concentración de la actividad económica y destacan las posibilidades que ofrece la red urbana europea. De este modo, se propone: compensar las diferencias de densidad de población entre territorios potenciando el 
desarrollo coordinado de ciudades en zonas mixtas y rurales, conectar los territorios procurando el acceso a los principales servicios, y promover la cooperación a diferentes niveles. En el mismo sentido, la Estrategia Europa 2020, base de la nueva política de cohesión 2014-2020, propone como prioridades el crecimiento inteligente, sostenible e integrador y establece una serie de objetivos principales que se traducen también en nacionales, si bien con escaso énfasis en el componente territorial (Lois González et al. 2013), circunstancia que trata de paliarse mediante la elaboración de la «Agenda Territorial de la Unión Europea 2020». Resultan especialmente interesantes determinadas fórmulas que promueve la nueva política de cohesión y que se corresponden con sistemas de gobernanza territorial, como las estrategias de Desarrollo Local Participativo y las Inversiones Territoriales Integradas (arts. 32 y 36 del Reglamento (UE) 1303/2013).

En el proceso de discusión del citado Libro Verde surgieron aportaciones como las del Foro de Expertos sobre la cohesión, la diversidad y el desarrollo territorial, en el que participó uno de los autores, que fueron recogidas por Fernández Tabales et al. (2009). Este Foro ofreció una definición de cohesión territorial en los siguientes términos:

«La cohesión territorial podría definirse como un principio para las actuaciones públicas encaminadas al logro de objetivos como crear lazos de unión entre los miembros de una comunidad territorial (cohesión social) y favorecer su acceso equitativo a servicios y equipamientos (equidad/justicia espacial), configurar un auténtico proyecto territorial común (identidad) partiendo del respeto a la diversidad y a las particularidades, articular y comunicar las distintas partes del territorio y romper las actuales tendencias hacia la polarización y desigualdad entre territorios (de la Unión Europea o de España) aprovechando las fortalezas y rasgos inherentes de cada uno de ellos. Se trata, además, de buscar la cohesión o coherencia interna del territorio, así como la mejor conectividad de dicho territorio con otros territorios vecinos.» (ODTA 2009)

Se trataría de un principio que incluye tres elementos: la articulación física entre las partes del territorio, la equidad territorial y la identificación de la comunidad con un proyecto en común. Son elementos interrelacionados, y prueba de ello es la importancia que tiene la conectividad y accesibilidad física en la equidad territorial (Ojeda 2008) o la forma en que la existencia de una identidad diferenciada y un sentido de pertenencia puede facilitar procesos de desarrollo basados en la eficiencia y en la equidad territorial (Precedo 2006). 


\section{EQUidAd TERRITORIAL A TRAVÉS DEL POLICENTRISMO}

Por equidad territorial entendemos, siguiendo el citado Foro, la «igualdad de oportunidades para alcanzar el desarrollo de la persona en todas las partes de un territorio». El concepto se vincula a la igualdad de oportunidades y de acceso a los bienes, servicios, equipamientos e infraestructuras necesarias para poder desarrollar una iniciativa o proyecto de vida en cualquier lugar. Su importancia a la hora de guiar las actuaciones públicas cobra sentido en la medida en que existen importantes desequilibrios y diferencias en la calidad de vida de los ciudadanos dependiendo de la localización, y estas diferencias se manifiestan especialmente entre ámbitos rurales y urbanos.

La equidad territorial no debe entenderse como igualdad absoluta sino como equilibrio. El territorio es, 'per se', anisotrópico: cada localidad presenta sus propias características y potencialidades. El equilibrio es posible a través de una relación adecuada entre dotación efectiva de recursos y servicios y las necesidades de la población. Es aquí donde la gestión territorial cobra un papel central y, en ella, accesibilidad y necesidad se convierten en las variables principales (Ojeda, 2008:16). La accesibilidad no debe entenderse únicamente como una mayor dotación de infraestructuras, también puede ser mejorada repensando la movilidad y el acceso a bienes y servicios (ODTA 2009). Ello lleva a plantear cómo distribuirlos y gestionarlos, por qué entes y con qué tipo de relaciones entre ellos. Éstas pueden ser descoordinadas, exclusivas y excluyentes (descentralización, 'public choice', concentración en manos de las Diputaciones...) o bien acogerse a formas de cooperación más eficientes: nuevas formas de gobernanza entre territorios/municipios y niveles políticoadministrativos; tanto en sentido horizontal (comarcas, mancomunidades, áreas metropolitanas...) como vertical (entre distintas administraciones e incluso con la participación de la iniciativa privada y la sociedad civil, caso de los consorcios).

Documentos como la ETE de 1999 y otros que la siguen ven el policentrismo funcional (cuyo objetivo es el desarrollo de diferentes polos periféricos para complementar la concentración de la actividad en el Pentágono europeo) como el modo de mejorar la equidad entre el centro y la periferia europea. El policentrismo se contempla a diferentes escalas, entre ellas las propias regiones, haciendo partícipes a las áreas rurales de este nuevo modelo de desarrollo. Sobre la base del propio patrimonio natural y cultural, primero, y a partir de lo que se ha dado en llamar nuevos servicios ecológicos e infraestructura verde después. Las regiones que cuentan con un gran número de ciudades de distintos niveles, pero sobre todo medias y pequeñas, pueden articular una red que les permita actuar cooperativamente facilitando servicios a los espacios rurales, que a su 
vez aportan sus propios servicios y recursos a sus regiones, configurando un nuevo espacio de desarrollo más imbricado, cohesionado y diverso ${ }^{3}$.

Partimos ahora de una revisada interrelación y complementariedad entre los entornos rurales y urbanos (sin hegemonías y una mayor 'deference' entre ambos) en la que los límites entre ellos resultan más difusos. Se mantiene la vieja idea de los polos de desarrollo, organizando el territorio a partir de los centros urbanos encargados de dinamizar sus entornos, pero cambian las condiciones y formas de esta dinamización. Los territorios toman un papel más proactivo y repolitizado. Se convierten en agentes activos de su propio desarrollo mediante una mayor participación de la población y los Grupos de Acción Local, junto a la administración local, en las políticas y actuaciones planteadas desde los distintos niveles de responsabilidad y competencia. Esta dinamización se puede traducir en fórmulas específicas para la equidad como los instrumentos de compensación intermunicipal, con los que se pretende compensar la diferencia entre unas partes y otras del territorio derivada de los diferentes usos y aprovechamientos del suelo autorizados en cada lugar, con el fin de lograr un modelo territorial más sostenible (Font y Perdigó 2002).

La accesibilidad debe alcanzar, según el Libro Verde, servicios como «la asistencia médica, la educación y la energía sostenible, acceso a internet de banda ancha, conexiones eficaces a redes de energía y fuertes vínculos entre las empresas y los centros de investigación» (CE 2008: 7). Es decir, el suministro a las zonas rurales abarca un inventario cada vez más amplio de servicios y actuaciones, y no solo los más básicos, cuya coordinación aconseja partir de estrategias territoriales locales integradas. Autores como Méndez (2006) o Pascual y García Cuesta (2008), partiendo del concepto de sistema productivo local, resaltan la importancia del acceso a intangibles como el conocimiento y la información para generar innovación y actividad económica en las propias áreas rurales. Ello pasa necesariamente por las ciudades intermedias que, sin ser centros metropolitanos, «cuentan con suficiente masa crítica y pueden actuar como intermediarios entre la gran ciudad y los espacios rurales» (Méndez 2006: 25). Queda claro que el ámbito más apropiado para ello es el supramunicipal y subregional (ODTA 2009), criterio reforzado por otros principios de larga tradición como son los de proximidad y subsidiariedad, y que se concreta en las nuevas áreas o regiones funcionales, ciudades-región... y el nuevo enfoque 'local/place based' en las políticas de desarrollo local (Barca 2009).

3 Vid. el tercer escenario, 'C', del proyecto ESPON Scenarios 2050 en comparación al 'B', policéntrico, y sobre todo al 'A', metropolitano - http://www.et2050.eu/-. 


\section{COOPERACIÓN INTERMUNICIPAL COMO PRÁCTICA DE GOBERNANZA TERRITORIAL}

Partiendo de unainterpretación que contempla lagobernanza como precondición para la cohesión territorial (Farinós 2008), pondremos el foco en las instituciones y estructuras políticas y administrativas que se constituyen para lograr de forma más eficaz la equidad territorial. La gobernanza es un proceso que se adapta a cada territorio en función de sus características y en el que la colaboración y la flexibilidad resultan aspectos clave. Atendiendo a ello y partiendo de la idoneidad de la escala supramunicipal-subregional, la cooperación intermunicipal resulta un elemento fundamental, tanto por las ventajas colaborativas que implica en términos de eficiencia y de accesibilidad a los bienes y servicios públicos, como por favorecer, en coherencia con los principios de subsidiariedad y proximidad, el cumplimiento de los principios de apertura, participación, responsabilidad, eficacia y coherencia que caracterizan la buena gobernanza (CE 2001).

La cooperación intermunicipal guarda relación con la articulación y la cohesión territorial (Farinós 2013), pero también con el debate sobre la escala óptima para la prestación de servicios y la actuación de los gobiernos. En este sentido, trabajos como el de Alesina y Spolaore (2008) buscan el tamaño óptimo de un país desde el análisis económico; otros, como el de Lago-Peñas y Martínez Vázquez (2013), se centran en el gobierno local desde una perspectiva politológica. En el segundo trabajo, como destacaba Simón (2013), se aprecian las implicaciones que tiene la cuestión de la escala tanto para la eficiencia económica en la prestación de servicios como para la responsabilidad y la dación de cuentas ('accountability'), el control de la corrupción, la participación ciudadana o la representación política. Y es que la ecuación entre más eficiencia (economía) y más democracia (política) no resulta fácil de resolver de forma aséptica o no participante.

Son diversas las razones que motivan a los municipios a asociarse. Para autores como De Mello y Lago-Peñas (Lago-Peñas y Martínez Vázquez 2013) es la voluntad de maximizar las economías de escala y de internalizar los 'spillovers' que se producen entre los municipios para reducir el coste de la prestación. Otros como Bel y Warner (2013) recogen, atendiendo a la literatura existente, los principales factores que favorecen la asociación: limitaciones financieras, generación de economías de escala, profesionalización de la gerencia y superar el microfundismo. Por el contrario, algunos de los elementos que la dificultan serían los costes de transacción, la heterogeneidad étnica de los municipios, la riqueza de la comunidad o las diferencias políticas. Así pues, los motivos en cada caso resultan heterogéneos y dependientes del contexto. 
La fórmula de cooperación en la que nos centraremos es la mancomunidad de municipios, regulada por el art. 44 de la Ley 7/1985, de 2 de abril, Reguladora de las Bases del Régimen Local —LBRL-y, a nivel valenciano, los arts. 91 a 107 de la Ley 8/2010, de 23 de junio, de la Generalitat, de Régimen Local de la Comunitat Valenciana - LRLCV ${ }^{4}$ - . La LBRL en dicho artículo 44 reconoce a los municipios «el derecho a asociarse con otros en mancomunidades para la ejecución en común de obras y servicios determinados de su competencia». Se trata de entidades que emanan de la voluntariedad de los municipios y del derecho a su libre asociación; son los municipios los que deciden su configuración. Por ello resultan más flexibles y adaptables. Además, su actuación a nivel supralocal permite la generación de economías de escala para prestar servicios en municipios pequeños y la posibilidad de una mayor rendición de cuentas y participación por la proximidad física al ciudadano. Por todo ello, la mancomunidad ha sido la fórmula de cooperación intermunicipal más extendida, aunque de momento ésta se limita básicamente a nivel administrativo (ODTA 2009). Por ello conviene analizar su impacto sobre la equidad territorial.

\section{El contexto VAlenciano}

Según datos del INE, la Comunitat Valenciana contaba en 2014 con un total de 5.004.844 habitantes, repartidos en 542 municipios. Ello arroja una población media de 9.234,03 habitantes por municipio y una densidad de 215 hab. $/ \mathrm{km}^{2}$. Son mejores cifras que la media española, pero esconden desequilibrios que suponen un reto para la prestación de servicios y la gestión del territorio. Además, desde un punto de vista territorial, la población urbana se concentra en grandes núcleos, generalmente litorales. Casi dos tercios de los municipios valencianos tienen menos de 5.000 habitantes, más de tres cuartas partes presentan una superficie menor que la media de los municipios españoles y menos de la mitad tienen una densidad superior a la media española (MPT, 2009)5.

A pesar de ello, el territorio valenciano ofrece potencialidades derivadas de su diversidad urbana. Tal y como destaca el volumen de la ETCV dedicado al sistema urbano, el gran número de ciudades medias hace que la Comunitat Valenciana

4 Afectada por la Ley 27/2013, de 27 de diciembre, de Racionalización y Sostenibilidad de la Administración Local. Nuevo texto consolidado en: http://www.femp.es/files/3580-769-fichero/ LBRL\%20CONSOLIDADA.pdf

5 Un buen diagnóstico puede encontrarse en el documento de Estrategia Territorial de la Comunidad Valenciana (ETCV) aprobada en 2011. 
presente uno de los sistemas de ciudades mejor distribuido y equilibrado, ofreciendo oportunidades para mejorar el acceso a bienes y servicios en todo el territorio, y representa un importante potencial en términos de equilibrio territorial. Sirviéndose de las áreas de influencia de las ciudades y en el marco de la complementariedad urbano-rural, en el documento de la ETCV se divide el territorio en quince áreas funcionales según criterios de polaridad territorial (en base a los flujos de movilidad por motivos de trabajo, consumo, ocio y provisión de servicios administrativos, y por los flujos de provisión de servicios avanzados a empresas). La ETCV destaca el policentrismo y el equilibrio del sistema de ciudades valenciano como una fortaleza en los objetivos de: mantener la diversidad y la vertebración del sistema de ciudades (objetivo 1), aplicar de forma eficiente los instrumentos de equidad territorial (objetivo 12) y desarrollar fórmulas innovadoras de gobernanza territorial (objetivo 25).

Pese a ello, para un adecuado acceso a los bienes y servicios es necesaria la cooperación entre las distintas administraciones y los actores privados, y ahí la situación es menos favorable. Los mismos documentos que contemplan como fortaleza la red de ciudades destacan como debilidades el déficit de gobernanza, planificación y cooperación supramunicipal e intercomunal. Además, los Planes de Acción Territorial -PAT_, planes integrales de ordenación territorial que deberían aplicar las recomendaciones de la ETCV en ámbitos supuestamente coincidentes con las áreas funcionales propuestas, no se han desarrollado. A ello se suma el escaso éxito de algunos de los instrumentos que se articularon para la compensación interterritorial por los diferentes usos del suelo permitidos y en los que la ETCV centraba su atención. Caso del Fondo de Equidad Territorial, que figuraba en la derogada Ley de Ordenación del Territorio y Protección del Paisaje (LOTPP) de 2004, pero que nunca se llegó a aplicar y que ha dejado de estar presente en la vigente Ley de Ordenación del Territorio, Urbanismo y Paisaje de la Comunitat Valenciana (LOTUP) de 2014.

A falta de los PAT integrales y del desarrollo legal de las comarcas(vid. Membrado 2013), la fórmula asociativa más extendida ha sido la mancomunidad, cuya importancia ha ido creciendo con los años (tabla 1). Con sus limitaciones y potencialidades por explotar, lo cierto es que la necesidad de generar economías de escala explica su proliferación. 
TABLA 1

PRESENCIA DE LAS MANCOMUNIDADES EN LA COMUNITAT VALENCIANA EN 1994, 2009 Y 2014

\begin{tabular}{c|c|c|c|c|c|c|c|c}
\hline Año & Provincias & $\begin{array}{c}\mathrm{N}^{0} \\
\text { Mancom. }\end{array}$ & $\begin{array}{c}\text { Población } \\
\text { total }\end{array}$ & $\begin{array}{c}\text { Población } \\
\text { en Mancom. }\end{array}$ & $\begin{array}{c}\% \\
\text { Población }\end{array}$ & $\begin{array}{c}\text { Municipios } \\
\text { totales }\end{array}$ & $\begin{array}{c}\text { Municipios } \\
\text { Mancom. }\end{array}$ & $\begin{array}{c}\% \\
\text { Municipios }\end{array}$ \\
\hline \multirow{4}{*}{1994} & Alacant & 15 & 1.288 .262 & 612.119 & 47,83 & 141 & 83 & 58,87 \\
\cline { 2 - 9 } & Castelló & 7 & 453.909 & 70.676 & 15,57 & 136 & 80 & 58,82 \\
\cline { 2 - 9 } & València & 23 & 2.160 .258 & 957.073 & 44,30 & 264 & 191 & 72,35 \\
\cline { 2 - 9 } & Total & 45 & 3.902 .429 & 1.643 .868 & 42,12 & 541 & 354 & 65,43 \\
\hline \multirow{4}{*}{2009} & Alacant & 24 & 1.891 .477 & 989.705 & 52,32 & 141 & 114 & 80,85 \\
\cline { 2 - 9 } & Castelló & 9 & 594.915 & 111.104 & 18,68 & 135 & 80 & 59,26 \\
\cline { 2 - 9 } & València & 28 & 2.543 .209 & 1.430 .252 & 56,24 & 266 & 231 & 86,84 \\
\cline { 2 - 9 } & Total & 61 & 5.029 .601 & 2.531 .061 & 50,32 & 542 & 425 & 78,41 \\
\hline \multirow{4}{*}{2014} & Alacant & 27 & 1.868 .438 & 1.058 .397 & 56,65 & 141 & 116 & 81,56 \\
\cline { 2 - 9 } & Castelló & 8 & 587.508 & 52.785 & 8,98 & 135 & 73 & 54,07 \\
\cline { 2 - 9 } & València & 28 & 2.548 .898 & 1.456 .743 & 57,15 & 266 & 236 & 88,72 \\
\cline { 2 - 9 } & Total & 63 & 5.004 .844 & 2.567 .925 & 51,31 & 542 & 425 & 78,41 \\
\hline
\end{tabular}

Fuente: Elaboración propia a partir de datos de D’Anjou (1994), MPT (2009) y Registro de entidades locales (Ministerio de Hacienda y de Administraciones Públicas).

El art. 91 de la LRLCV precisa que las mancomunidades son «asociaciones voluntarias de municipios que se constituyen para gestionar y/o ejecutar planes, realizar proyectos y obras o prestar servicios de su competencia». Dada esta flexibilidad, sus funciones resultan muy heterogéneas (Riera et al., 2005), con una evolución tendente a un mayor número de funciones cada vez más diversas, circunstancia que Barreiro (2005) interpreta como el tránsito de la «mancomunidad tradicional» a la «mancomunidad evolucionada».

En el territorio valenciano existen mancomunidades que se dedican a prestar los servicios mínimos, como la gestión del agua o la recogida de residuos sólidos, pero también las hay que desarrollan servicios para los ciudadanos en muy diversos ámbitos junto con otro tipo de servicios para los propios municipios, convirtiéndose así en centros de apoyo a la gestión. Los fines más frecuentes son los servicios sociales, las actividades culturales, el fomento del turismo, la recogida y tratamiento de residuos sólidos y el fomento de actividades económicas, seguidos de la protección del medio ambiente y los servicios educativos (MPT, 2009). Por tanto, entre sus servicios más habituales figuran los servicios mínimos obligatorios que se recogen en los arts. 34 de la LRLCV y 26 de la LBRL, pero también otros no obligatorios para los municipios, una muestra de su evolución. 
6. La Mancomunitat de la Ribera Alta: caracterización, funciones e impacto TERRITORIAL

Teniendo como referencia la ETCV, el análisis se concreta en la comarca de la Ribera Alta, al pretender estudiar el rendimiento real y potencial de la mancomunidad en términos de equidad territorial. Esta comarca agrupa 35 municipios y 221.299 habitantes, con una densidad de $228 \mathrm{hab} . / \mathrm{km}^{2}$. La mayor parte de estos municipios se incluyen en el Área Funcional de la Ribera del Xúquer, si bien algunos de ellos se adscriben a las Áreas Funcionales de Valencia y de Xàtiva. Además, el Área Funcional de la Ribera del Xúquer abarca una escala más amplia en la que también se incluye la mayor parte de la comarca de la Ribera Baixa (ver figura 1).

La ETCV divide el territorio valenciano en tres grandes zonas en sentido litoralinterior: la cota 100, la franja intermedia y el sistema rural. La Ribera Alta queda incluida en la cota 100, el área más densa y con mayor concentración de población y de actividad económica, con predominio de los servicios y de la agricultura de regadío. Por lo que respecta al sistema de ciudades, cabe destacar el fenómeno de las conurbaciones y las áreas urbanas integradas (AUI), agrupaciones de municipios consideradas como unidades que funcionan conjuntamente según criterios como la continuidad urbanística, los flujos de movilidad, la actividad económica y el mercado de trabajo. Se trata de un proceso que se ha desarrollado en las últimas décadas, ligado a un crecimiento demográfico descentralizado y a un patrón de urbanización difusa, y que ha provocado cambios en la jerarquía de ciudades del territorio valenciano (Salom, 2011). Según la ETCV, en la Ribera Alta existen varias AUI, siendo la más importante la de Alzira, compuesta por la conurbación de Alzira, Carcaixent y Algemesí, si bien este proceso también se ha desarrollado en la comarca en los casos de Montserrat - Montroi (Montserrat y Montroi), Llombai (Llombai, Catadau y Alfarp), Carlet (Carlet y Benimodo), Alberic (Alberic y Gavarda), Alcàntera del Xúquer - Beneixida (Alcàntera del Xúquer, Càrcer y Beneixida), Villanueva de Castellón (Villanueva de Castellón y Senyera) y l'Ėnova - Manuel ('Ėnova y Manuel).

En cuanto al sistema nodal que propone la ETCV, basado en las áreas urbanas que crean polaridad y permiten el acceso a los bienes y servicios a su entorno, la Ribera Alta se enmarca dentro del sistema urbano de ciudades medias, de importancia estratégica para vertebrar el territorio. Dentro de este sistema se contemplan centros de polaridad principal y complementaria. Los primeros ejercen influencia sobre toda el área funcional y deben agrupar la mayor parte de los equipamientos supramunicipales de vertebración. Los segundos influyen territorialmente sobre municipios del área funcional y, como mínimo, deben 
tener un equipamiento supramunicipal. En el Área Funcional de la Ribera del Xúquer hay tres centros: el centro de polaridad principal es la AUI de Alzira, mientras que los centros de polaridad complementaria son las AUI de Carlet y de Sueca. Por tanto, en la comarca de la Ribera Alta se encuentran el centro de polaridad principal y uno de los dos complementarios del Área Funcional.

La valoración de aspectos como la cohesión y la equidad territorial se enfrenta a la difícil tarea de su medición (ODTA, 2009; Ojeda, 2008; Lois et al., 2013; Pillet et al., 2013). Tomaremos como referencia elementos que, aunque serán necesariamente limitados, nos pueden servir para destacar aproximadamente qué impacto tiene la acción de la mancomunidad ('proxy indicators'). Hemos analizado las prestaciones que ofrece la Mancomunitat de la Ribera Alta — MANRA — valorando en qué medida provee de servicios a los municipios más pequeños a los que de otro modo no podrían acceder, y qué tipo de municipios son los que más utilizan los servicios mancomunados. Ello nos permitirá valorar si la acción de la mancomunidad repercute en una mayor equidad de acceso a los servicios en todos los municipios.

Conviene señalar que, en la comarca de la Ribera Alta, MANRA no es la única mancomunidad constituida, aunque sí la única que agrupa a todos sus municipios, como se aprecia en la figura 1. Los municipios de Alcàntera del Xúquer, Càrcer, Cotes y Sellent forman una mancomunidad para el abastecimiento de agua potable y la atención inmediata a personas en riesgo de exclusión. Manuel, Rafelguaraf, Sant Joanet, Senyera, Villanueva de Castellón y l'Énova han constituido una mancomunidad para servicios de bienestar social. La Mancomunitat del Marquesat (Alfarp, Catadau y Llombai) presta fundamentalmente los servicios de aguas potables, ambulancias y depuración de aguas residuales y la Mancomunitat de la Vall dels Alcalans (Montserrat, Montroi y Real) los de aguas potables, alcantarillado, limpieza viaria y recogida de basuras, matadero y urbanismo. Todas ellas se constituyeron previamente a la que agrupa a toda la comarca, constituida en 1996, que es objeto de este análisis. Es posible, por tanto, que algunos servicios que ya prestan las primeras no sean solicitados a la MANRA, circunstancia que debemos tener presente.

Para analizar la relación de servicios de la mancomunidad nos hemos basado fundamentalmente en la Memoria anual del año 2014. Cabe destacar que MANRA presta dos tipos de servicios: generales y opcionales, siendo estos segundos los que analizaremos. En la categoría de servicios de carácter general se engloban diferentes tipos de servicios: cesión gratuita de equipamiento a los ayuntamientos para actos públicos, estudios comarcales, premios literarios o culturales, promoción de actividades deportivas o culturales, jornadas de de formación, jornadas de promoción del uso del valenciano (tanto en el material propio como mediante un 
FIgURA 1

ÁREAS FUNCIONALES, CENTROS DE POLARIDAD Y MANCOMUNIDADES EN LA RIBERA ALTA

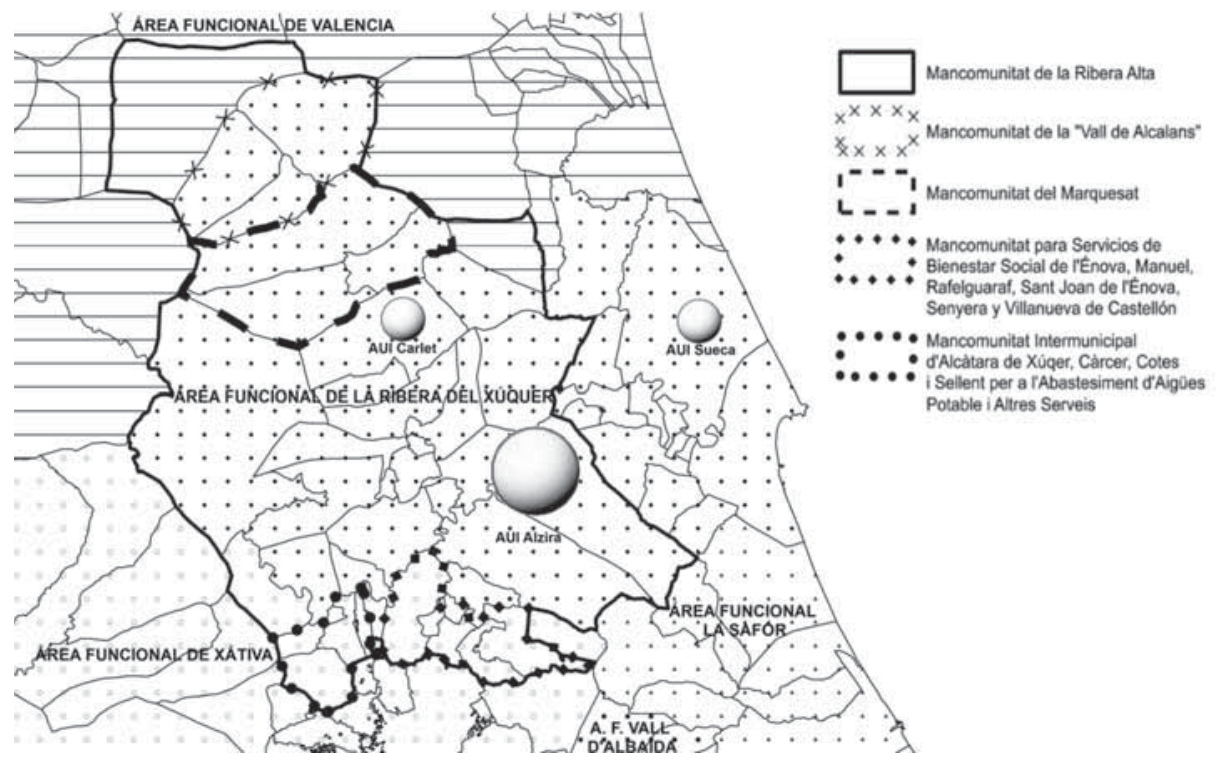

Fuente.: Elaboración propia a partir de Conselleria de Medi Ambient, Aigua, Urbanisme i Habitatge (2011d) y Registro de entidades locales (Ministerio de Hacienda y de AA.PP.). Los autores agradecen la colaboración de Enrique Peiró Sánchez-Manjavacas en la preparación de la figura.

servicio de traducción y corrección a los ayuntamientos). Debe destacarse, dentro de los servicios generales, la Agencia de Desarrollo Comarcal (que incluye un servicio de inserción laboral, un punto de asesoramiento empresarial y una agencia para el fomento de la innovación comercial, además de otros servicios opcionales) y la Agencia comarcal para la gestión de la diversidad (AMICS). Entre los servicios ordinarios, que no requieren adhesión a la Mancomunidad de La Ribera, dado que se prestan vía «Consorcio de la Ribera», figuran también el PATER (Pacto Territorial por el Empleo de la Ribera), Riberaturisme y la Agencia Energética de la Ribera -AER-.

Para averiguar cómo los municipios de diferentes tamaños de la comarca se benefician de los servicios prestados por la mancomunidad hemos establecido primero una tipología de municipios por intervalos de población (ver tabla 2). Estos intervalos se han escogido en base a algunos criterios convencionales para la clasificación de los municipios: 1.000 habitantes es un límite que 
frecuentemente se ha considerado para clasificar al municipio como rural y pequeño; 5.000 y 20.000 habitantes son los intervalos en los que se basa el art. 34 de la LRLCV para establecer los servicios mínimos obligatorios. Aunque toda el área comarcal se incluya en el sistema de ciudades medias y en la cota 100, alejada del sistema rural, lo cierto es que contiene gran variedad demográfica y económica. Cuenta, por una parte, con ciudades medias con economías de servicios y equipamientos pero, a la vez, existen muchos municipios que, por número de habitantes o densidad, tienen dificultades para acceder a los servicios, cumpliendo algunas de las condiciones que permiten calificar un territorio como rural (MARM, 2009). Así, más de dos terceras partes de los municipios tienen menos de 5.000 habitantes, seis de ellos tienen menos de 1.000 y nueve tienen una densidad $<100 \mathrm{hab} . / \mathrm{km}^{2}$. A su vez, aunque algunos núcleos de la comarca tienen una economía de servicios avanzada, en muchos otros de su área de influencia el sector predominante es el agrario. Por tanto, aunque no estamos en un sistema propiamente rural según la tipología de la ETCV, existen diferencias en las características de los municipios que derivan en problemas de acceso a los servicios públicos y, por tanto, en problemas de inequidad.

TABLA 2

DISTRIBUCIÓN DE LOS MUNICIPIOS DE LA RIBERA ALTA POR N ${ }^{\circ}$ DE HABITANTES

\begin{tabular}{|c|c|l|}
\hline Habitantes & $N^{\circ}$ municipios & \multicolumn{1}{|c|}{ Municipios } \\
\hline$<1000$ & 6 & L'Ènova, Beneixida, Benimuslem, Sant Joanet, Sellent, Cotes \\
\hline $1000-5000$ & 18 & $\begin{array}{l}\text { Alcàntera del Xúquer, Alfarp, Antella, Benimodo, Càrcer, Catadau, Gavarda, } \\
\text { Llombai, Manuel, Massalavés, Montroi, la Pobla Llarga, Rafelguaraf, Real, } \\
\text { Senyera, Sumacàrcer, Tous }\end{array}$ \\
\hline$>5.000-10.000$ & 4 & Villanueva de Castellón, Montserrat, Turís, Guadassuar \\
\hline$>10.000-20.000$ & 4 & Alcúdia, Alginet, Benifaí, Carlet \\
\hline$>20.000$ & 3 & Algemesí, Alzira, Carcaixent \\
\hline
\end{tabular}

Fuente.: Elaboración propia a partir del Portal de información Argos (Generalitat Valenciana).

Teniendo en cuenta la distribución por tamaño poblacional de los municipios, para cada servicio opcional (un total de 25 que recoge la tabla 3), hemos extraído tanto el número total de municipios adheridos como su desglose por tamaño de población, destacando asimismo qué porcentaje de municipios de cada intervalo está adherido a cada servicio. Por otra parte, hemos clasificado los servicios por tipologías (vid. la segunda columna de la tabla 3), resultando una serie de categorías de servicios que nos puedan servir de referencia a pesar de la gran variedad inicial. 
TABLA 3

\section{SERVICIOS OPCIONALES DE LA MANCOMUNITAT Y \% DE MUNICIPIOS ADHERIDOS EN CADA INTERVALO DE POBLACIÓN}

\begin{tabular}{|c|c|c|c|c|c|c|c|c|c|c|}
\hline & \multirow{2}{*}{ Servicio } & \multirow{2}{*}{$\begin{array}{l}\text { Tipo de } \\
\text { servicio }\end{array}$} & \multirow{2}{*}{ Tarifa del servicio } & \multicolumn{2}{|c|}{ Adhesiones } & \multirow{2}{*}{$<1000$} & \multirow{2}{*}{$\begin{array}{l}1000- \\
5000\end{array}$} & \multirow{2}{*}{$\begin{array}{l}>5000- \\
10000\end{array}$} & \multirow{2}{*}{$\begin{array}{c}>10000- \\
20000\end{array}$} & \multirow{2}{*}{$\stackrel{>}{20000}$} \\
\hline & & & & $\mathrm{n}^{0}$ & $\%$ & & & & & \\
\hline 1 & Biodiesel (AER) & $\begin{array}{l}\text { Tratamiento } \\
\text { residuos }\end{array}$ & Gratuito & 30 & 86 & 83 & 94 & 75 & 100 & 33 \\
\hline 2 & $\begin{array}{l}\text { Residuos: envases } \\
\text { ligeros }\end{array}$ & $\begin{array}{l}\text { Tratamiento } \\
\text { residuos }\end{array}$ & 0,798€ hab./año & 24 & 69 & 100 & 72 & 50 & 100 & 0 \\
\hline 3 & $\begin{array}{l}\text { Animales } \\
\text { abandonados }\end{array}$ & Animales & 0,60/0,40/0,20 hab/año & 24 & 69 & 66 & 61 & 100 & 100 & 33 \\
\hline 4 & SEAFI & $\begin{array}{l}\text { Servicios } \\
\text { sociales }\end{array}$ & $0,47 €$ hab./año & 23 & 66 & 66 & 78 & 50 & 100 & 0 \\
\hline 5 & $\begin{array}{l}\text { Residuos: papel y } \\
\text { cartón }\end{array}$ & $\begin{array}{c}\text { Tratamiento } \\
\text { residuos }\end{array}$ & Gratuito & 22 & 63 & 100 & 67 & 50 & 50 & 0 \\
\hline 6 & Educación vial & Formación & Gratuito & 21 & 60 & 50 & 72 & 50 & 50 & 33 \\
\hline 7 & Gestión de multas & $\begin{array}{c}\text { Movilidad y } \\
\text { tráfico }\end{array}$ & $10,50 € / \mathrm{multa}$ & 20 & 57 & 17 & 61 & 100 & 75 & 33 \\
\hline 8 & $\begin{array}{l}\text { UPD Drogode- } \\
\text { pendencia }\end{array}$ & $\begin{array}{c}\text { Servicios } \\
\text { sociales }\end{array}$ & 5,25€ hab./año & 19 & 54 & 17 & 61 & 75 & 0 & 0 \\
\hline 9 & OMIC & $\begin{array}{l}\text { Promoción } \\
\text { económica }\end{array}$ & Gratuito & 19 & 54 & 50 & 56 & 75 & 75 & 0 \\
\hline 10 & $\begin{array}{l}\text { Franqueo pagado } \\
\text { (Correos) }\end{array}$ & $\begin{array}{l}\text { Asistencia a } \\
\text { municipios }\end{array}$ & Gratuito & 17 & 49 & 17 & 50 & 50 & 75 & 66 \\
\hline 11 & $\begin{array}{l}\text { Mercado Eléctrico } \\
\text { (AER) }\end{array}$ & Energía & Gratuito & 17 & 49 & 33 & 56 & 50 & 75 & 0 \\
\hline 12 & Gestión de archivos & $\begin{array}{l}\text { Asistencia a } \\
\text { municipios }\end{array}$ & $90 €$ módulo & 16 & 46 & 33 & 50 & 25 & 50 & 66 \\
\hline 13 & $\begin{array}{l}\text { Gestor de energía } \\
\text { (AER) }\end{array}$ & Energía & Gratuito & 16 & 46 & 50 & 44 & 25 & 100 & 0 \\
\hline 14 & EPA Valencia & Formación & $\begin{array}{l}\text { Valencià: } 2 € \text { /alumn. } \\
\text { Reglada:43€/alum. }\end{array}$ & 15 & 43 & 50 & 67 & 0 & 50 & 0 \\
\hline 15 & Licencias ambientales & $\begin{array}{l}\text { Asistencia a } \\
\text { municipios }\end{array}$ & $200 €$ & 14 & 40 & 50 & 28 & 25 & 100 & 33 \\
\hline 16 & Servicio de grúa & $\begin{array}{l}\text { Movilidad y } \\
\text { tráfico }\end{array}$ & Gratuito & 13 & 37 & 50 & 39 & 25 & 50 & 0 \\
\hline 17 & Recogida ropa usada & $\begin{array}{c}\text { Tratamiento } \\
\text { residuos }\end{array}$ & Gratuito & 9 & 26 & 33 & 22 & 25 & 25 & 33 \\
\hline 18 & $\begin{array}{l}\text { Servicios sociales } \\
\text { grales }\end{array}$ & $\begin{array}{c}\text { Servicios } \\
\text { sociales }\end{array}$ & 5,70€ hab./año & 7 & 20 & 17 & 28 & 25 & 0 & 0 \\
\hline 19 & $\begin{array}{l}\text { Serv. techos solares } \\
\text { (AER) }\end{array}$ & Energía & Gratuito & 7 & 20 & 0 & 11 & 50 & 50 & 33 \\
\hline 20 & $\begin{array}{l}\text { Suministro agua } \\
\text { potable }\end{array}$ & Agua & Gratuito & 6 & 17 & 17 & 6 & 25 & 50 & 33 \\
\hline 21 & ADL Compartido & $\begin{array}{l}\text { Promoción } \\
\text { económica }\end{array}$ & $20 \%$ & 6 & 17 & 33 & 11 & 25 & 0 & 33 \\
\hline 22 & $\begin{array}{l}\text { Serv. bicicletas } \\
\text { AMBICI }\end{array}$ & $\begin{array}{c}\text { Movilidad y } \\
\text { tráfico }\end{array}$ & Gratuito & 5 & 14 & 0 & 17 & 0 & 25 & 100 \\
\hline 23 & $\begin{array}{l}\text { Asist. técnica } \\
\text { industrial }\end{array}$ & $\begin{array}{c}\text { Asistencia a } \\
\text { municipios }\end{array}$ & Gratuito & 4 & 11 & 0 & 11 & 25 & 25 & 0 \\
\hline 24 & Servicio dependencia & $\begin{array}{l}\text { Servicios } \\
\text { sociales }\end{array}$ & Gratuito & 3 & 9 & 0 & 11 & 25 & 0 & 0 \\
\hline 25 & Asistencia informática & $\begin{array}{l}\text { Asistencia a } \\
\text { municipios }\end{array}$ & 3.180€ módulo & 1 & 3 & 17 & 0 & 0 & 0 & 0 \\
\hline
\end{tabular}

\begin{tabular}{l|l|l|l|}
\hline$<49 \%$ & $50 \%-74 \%$ & $75 \%-100 \%$ & Negrita: los cinco servicios con más adhesiones en cada caso.
\end{tabular}

Fuente: Elaboración propia a partir de Mancomunitat de la Ribera Alta (2015).

Estudios Geográficos, Vol. LXXVIII, 283, pp. 465-491, julio-diciembre 2017 ISSN: 0014-1496, eISSN: 1988-8546, doi: 10.3989/estgeogr.201716 
Como muestra la tabla 3, el servicio opcional con más adhesiones es el de recogida de aceite usado para la producción de biodiesel, seguido de servicios como el tratamiento de envases ligeros, el de recogida y control de animales abandonados, el de atención especializada a la familia y la infancia, y el tratamiento de papel y cartón. Así pues, entre los servicios con más adhesiones destaca el tratamiento de residuos, pero también servicios sociales como el SEAFI y la UPC de drogodependencia, y la Oficina de Mediación e Información al Consumidor (OMIC). Cabe destacar el escaso interés por algunos servicios de asistencia más técnica, informática e industrial que, junto al servicio de dependencia (dados los problemas de financiación sufridos), son los que menos acogida han tenido. Una prueba manifiesta de la función, más asistencial que de competitividad territorial, que se otorga a la mancomunidad.

Sin embargo, estos datos generales no muestran las diferencias de comportamiento entre los diferentes tipos de municipios. Así, las tres ciudades de más de 20.000 habitantes sólo muestran cierto interés por los servicios de préstamo de bicicletas AMBICI, de gestión de archivos y de franqueo pagado (servicios relacionados con la movilidad y la asistencia administrativa). Ningún otro servicio tiene más de una adhesión por parte de alguno de estos municipios. Entre el resto de intervalos, aunque existen menos diferencias, también se observan algunos matices a destacar. Los cuatro municipios de entre 10.000 y 20.000 habitantes, además de estar adheridos al servicio de biodiesel, de tratamiento de envases ligeros, al de animales abandonados y al SEAFI, también lo están a otro tipo de servicios como el programa «Gestors d'energia» y el servicio de licencias ambientales, es decir, servicios relativos a la energía y la sostenibilidad urbana que tienen escasa acogida en el resto de intervalos.

Existen diferencias apreciables entre los municipios de menos de 5.000 habitantes y los de los demás intervalos por encima de 5.000. Así, servicios como el de recogida de animales, gestión de multas, OMIC y, en cierta medida, el servicio de techos solares, tienen mayor acogida en los municipios de más de 5.000 habitantes que en los de menos. Por el contrario, el servicio de tratamiento de papel y cartón y los servicios de formación (seguridad vial y, sobre todo, la Educación Permanente de Adultos —EPA—) están más presentes en los municipios de menos de 5.000 habitantes. Dentro de estos, los servicios de tratamiento de residuos (sobre todo envases ligeros y papel y cartón) son los que tienen más acogida entre los municipios de menos de 1.000 habitantes. Por lo que respecta a los municipios de entre 1.000 y 5.000 habitantes, además de estos servicios tiene especial relevancia el SEAFI y los servicios de formación, aunque otros como la UPC de drogodependencia o el 
de gestión de multas tienen también una presencia destacable dentro de los 18 municipios que integran este intervalo.

En síntesis, los municipios solicitan diferentes tipos de servicios en función de su población. Mientras que los municipios menores se adhieren a servicios de carácter más básico, los mayores lo hacen a servicios más especializados, con el claro umbral de los 20.000 habitantes. En los intervalos inferiores las diferencias no son tan relevantes, limitándose a algunos matices y servicios concretos. Cabe remarcar que, por porcentaje de adhesiones, no es sustancialmente superior en los municipios más pequeños que en los intervalos superiores hasta los 20.000 habitantes, si bien es cierto que casi todos los municipios que forman parte de otra mancomunidad de ámbito más reducido son municipios de menos de 5.000 habitantes.

Así pues, se observa una dinámica que, aunque con los matices mencionados, no difiere sustancialmente entre los municipios por debajo de 20.000 habitantes, al menos no en términos de mayor o menos adhesión a los servicios opcionales de la mancomunidad (tabla 4). Prueba de ello es que el municipio adherido a más servicios es Carlet, con más de 15.000 habitantes, así como el elevado número de servicios opcionales a los que se adhiere Alberic (municipio de algo más de 10.000 habitantes). No obstante, y siendo la mayor parte de municipios de la comarca de escasa población, lo cierto es que gran parte de ellos se adhieren a numerosos servicios, si bien algunos de menos de 1.000 habitantes se encuentran también entre los que menos servicios opcionales tienen. Una hipótesis posible es que ello pueda deberse a que en esos casos los municipios forman también parte de otras mancomunidades, como ya se ha comentado. Otra, menos probable, que al contar con menor población las necesidades fueran distintas a las que tratan de cubrir los servicios opcionales que presta la mancomunidad. Lo que sí resulta claramente visible es la escasa acogida de los servicios opcionales de la mancomunidad por parte de los tres municipios mayores de 20.000 habitantes. Ello sí denota claramente las diferentes características, necesidades y capacidades (autosuficiencia) de estos municipios.

En suma, tal y como se muestra en la figura 2, existe una modesta correlación entre el número de habitantes de cada municipio y el número de adhesiones a servicios opcionales de la mancomunidad. Esto contrasta con la apenas perceptible relación existente entre las adhesiones y otros factores como la densidad de población (figura 3) o el presupuesto medio per cápita (figura 4) (datos de 2014). Tampoco se observa, en la tabla 4, que exista una clara relación entre el número de servicios opcionales objeto de adhesión y el partido de gobierno local. 
TABLA 4

MUNICIPIOS POR NÚMERO DE SERVICIOS OPCIONALES CONTRATADOS

\begin{tabular}{|c|c|c|c|c|c|c|c|c|}
\hline & \multirow{2}{*}{ Municipio } & \multirow{2}{*}{$\begin{array}{l}\text { Adhesiones } \\
\text { a servicios } \\
\text { opcionales }\end{array}$} & \multirow{2}{*}{$\begin{array}{l}\text { Habitantes } \\
\quad(2014)\end{array}$} & \multicolumn{2}{|c|}{$\begin{array}{l}\text { Densidad } \\
\left(\mathrm{Hab} . / \mathrm{km}^{2}\right)\end{array}$} & \multicolumn{2}{|c|}{$\begin{array}{l}\text { Presupuesto medio por } \\
\text { habitante } 2014(€)\end{array}$} & \multirow{2}{*}{$\begin{array}{l}\text { Partido } \\
\text { Político } \\
(2014)\end{array}$} \\
\hline & & & & $\mathrm{Hab} / \mathrm{km}^{2}$ & \begin{tabular}{|c|} 
Base comarcal \\
100 \\
\end{tabular} & Euros & $\begin{array}{c}\text { Base comarcal } \\
100 \\
\end{array}$ & \\
\hline $1^{0}$ & Carlet & 16 & 15.351 & 337 & 148 & 611,64 & 86 & PP \\
\hline $2^{\circ}$ & Rafelguaraf $* * * *$ & 15 & 2.426 & 149 & 65 & 581,44 & 81 & PSOE \\
\hline $3^{\circ}$ & Càrcer* & 15 & 1.952 & 263 & 115 & 752,61 & 105 & $\mathrm{PP}$ \\
\hline $4^{0}$ & Sumacàrcer & 15 & 1.223 & 61 & 27 & 820,51 & 115 & PSOE \\
\hline $5^{0}$ & Antella & 14 & 1.343 & 76 & 33 & 615,92 & 86 & PSOE \\
\hline $6^{0}$ & Gavarda & 14 & 1.125 & 144 & 63 & 620,35 & 87 & $\mathrm{PP}$ \\
\hline $7^{0}$ & Benimodo & 13 & 2.254 & 180 & 79 & 788,64 & 111 & $\mathrm{PP}$ \\
\hline $8^{\circ}$ & Beneixida & 13 & 686 & 214 & 94 & $1.135,02$ & 159 & PSOE \\
\hline $9^{\circ}$ & Sant Joanet ${ }^{* * * *}$ & 13 & 486 & 261 & 114 & 770,76 & 108 & PSOE \\
\hline $10^{\circ}$ & Alberic & 13 & 10.826 & 402 & 176 & 738,84 & 104 & $\mathrm{PP}$ \\
\hline $11^{\circ}$ & Massalavés & 13 & 1.617 & 216 & 95 & 619,82 & 87 & $\mathrm{PP}$ \\
\hline $12^{\circ}$ & $\begin{array}{l}\text { Villanueva } \\
\text { de Castellón**** }\end{array}$ & 12 & 7.321 & 361 & 158 & 699,14 & 98 & PP \\
\hline $13^{\circ}$ & Montserrat $^{* * *}$ & 12 & 7.202 & 158 & 69 & 725,80 & 102 & PSOE \\
\hline $14^{\circ}$ & Senyera $* * * *$ & 12 & 1.174 & 578 & 236 & 591,10 & 83 & $\mathrm{PP}$ \\
\hline $15^{\circ}$ & Guadassuar & 12 & 5.928 & 168 & 74 & 733,30 & 103 & $\mathrm{PP}$ \\
\hline $16^{\circ}$ & Benimuslem & 12 & 668 & 160 & 70 & 781,04 & 109 & PSOE \\
\hline $17^{\circ}$ & Tous & 11 & 1.268 & 10 & 4 & $1.447,42$ & 203 & PP \\
\hline $18^{\circ}$ & La Pobla Llarga & 10 & 4.254 & 448 & 196 & 604,87 & 85 & PP \\
\hline $19^{\circ}$ & Montroi ${ }^{* * *}$ & 10 & 2.857 & 91 & 40 & 716,02 & 100 & PSOE \\
\hline $20^{\circ}$ & Llombai** & 10 & 2.787 & 50 & 22 & 551,48 & 77 & PP \\
\hline $21^{\circ}$ & Alfarp** & 10 & 1.553 & 75 & 33 & 807,62 & 113 & $\mathrm{PP}$ \\
\hline $22^{\circ}$ & Alginet & 9 & 13.060 & 543 & 238 & 684,86 & 96 & BLOC \\
\hline $23^{\circ}$ & Benifaió & 9 & 11.819 & 587 & 257 & 713,51 & 100 & $\mathrm{PP}$ \\
\hline $24^{\circ}$ & Alcàntera del Xúquer* & 9 & 1.350 & 405 & 118 & 618,43 & 87 & PSOE \\
\hline $25^{\circ}$ & l'Alcúdia & 9 & 11.615 & 491 & 215 & 751,70 & 105 & PSOE \\
\hline $26^{\circ}$ & Algemesí & 8 & 27.808 & 670 & 294 & 658,84 & 92 & $\mathrm{PP}$ \\
\hline $27^{\circ}$ & Catadau** & 8 & 2.754 & 78 & 34 & 588,86 & 83 & $\mathrm{PP}$ \\
\hline $28^{\circ}$ & Real $^{* * *}$ & 7 & 2.321 & 127 & 56 & 742,34 & 104 & AEA \\
\hline $29^{\circ}$ & l'Ènova**** & 7 & 977 & 127 & 56 & 517,44 & 73 & PSOE \\
\hline $30^{\circ}$ & Cotes ${ }^{*}$ & 7 & 365 & 58 & 25 & 754,52 & 105 & PP \\
\hline $31^{\circ}$ & Turís & 6 & 6.588 & 82 & 36 & 894,11 & 125 & $\mathrm{PP}$ \\
\hline $32^{\circ}$ & Sellent* & 6 & 397 & 28 & 12 & 894,21 & 125 & $\mathrm{PP}$ \\
\hline $33^{\circ}$ & Carcaixent & 5 & 20.613 & 348 & 153 & 703,58 & 97 & PP \\
\hline $34^{\circ}$ & Manuel**** & 5 & 2.543 & 420 & 184 & 490,29 & 69 & GIP \\
\hline $35^{\circ}$ & Alzira & 3 & 44.518 & 403 & 178 & 772,41 & 101 & $\mathrm{PP}$ \\
\hline- & Comarca & - & 221.299 & 228 & 100 (Base) & 713,53 & 100 (Base) & \\
\hline
\end{tabular}

* Alcàntera del Xúquer, Càrcer, Cotes y Sellent forman ya una mancomunidad para el abastecimiento de agua potable y la atención a situaciones de exclusión social.

** Alfarp, Catadau y Llombai forman también la Mancomunitat del Marquesat, que presta servicios de aguas potables, ambulancias y depuración de aguas residuales.

*** Montroi, Montserrat y Real forman también la Mancomunitat «la Vall dels Alcalans», que presta servicios de aguas potables, alcantarillado, limpieza viaria y recogida de basuras, matadero y urbanismo.

**** Manuel, Rafelguaraf, Sant Joanet, Senyera, Villanueva de Castellón y l'Ènova forman ya una mancomunidad para el sostenimiento de los servicios sociales.

Estudios Geográficos, Vol. LXXVIII, 283, pp. 465-491, julio-diciembre 2017

ISSN: 0014-1496, eISSN: 1988-8546, doi: 10.3989/estgeogr.201716 
FIGURA 2

CORRELACIÓN ENTRE NÚMERO DE HABITANTES DE LOS MUNICIPIOS (Y) Y SERVICIOS OPCIONALES DE LA MANCOMUNIDAD (X)

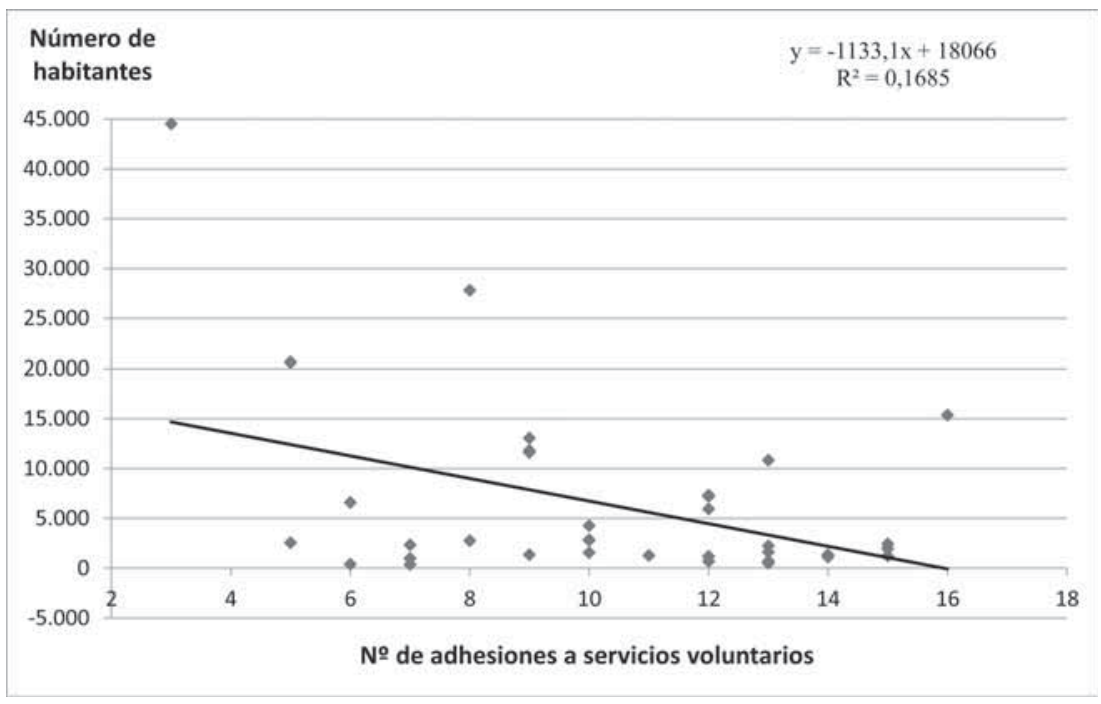

FIGURA 3

CORRELACIÓN ENTRE LA DENSIDAD (HAB/KM2) DE LOS MUNICIPIOS (Y) Y SERVICIOS OPCIONALES DE LA MANCOMUNIDAD (X)

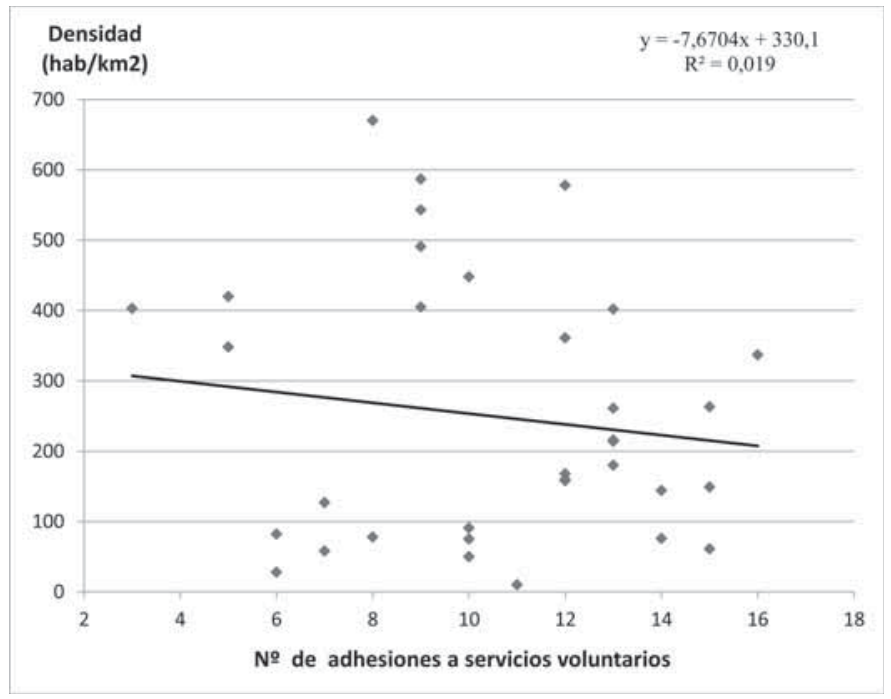

Estudios Geográficos, Vol. LXXVIII, 283, pp. 465-491, julio-diciembre 2017 ISSN: 0014-1496, eISSN: 1988-8546, doi: 10.3989/estgeogr.201716 
FIGURA 4

CORRELACIÓN ENTRE EL PRESUPUESTO MEDIO PER CÁPITA DE LOS MUNICIPIOS (Y) Y SERVICIOS OPCIONALES DE LA MANCOMUNIDAD (X)

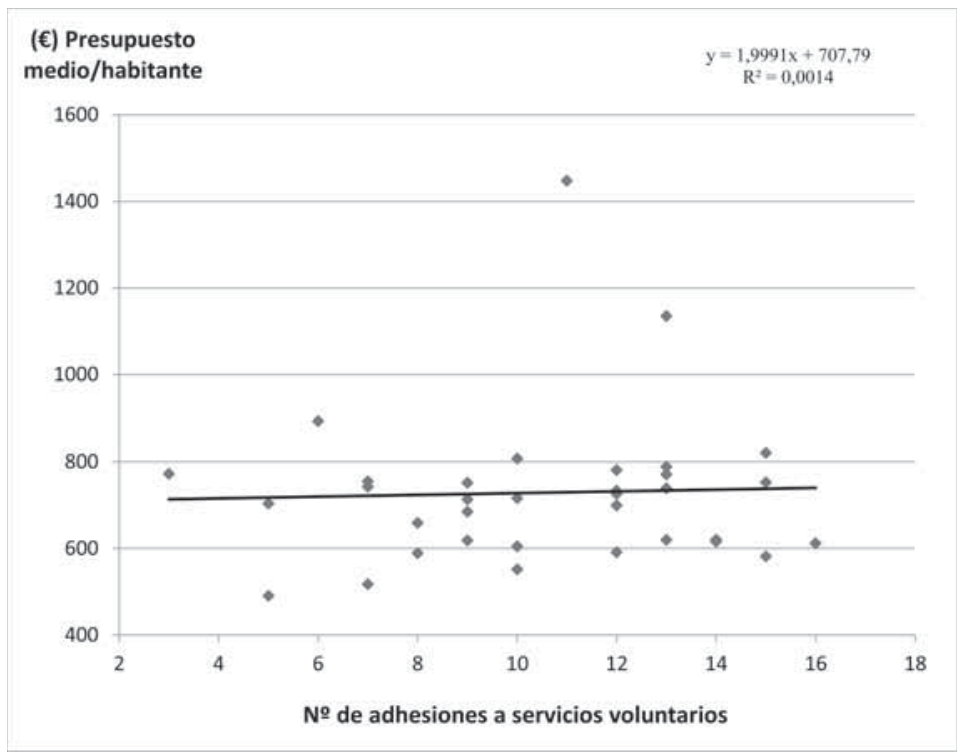

Fuente.: Mancomunitat de la Ribera Alta (2015), Portal de información Argos (Generalitat Valenciana) y elaboración propia.

En definitiva, la mayor contribución de MANRA a la equidad territorial tiene que ver con la generación de economías de escala que permiten prestar más servicios. No existe una planificación que se plantee como objetivo paliar la inequidad territorial, ni se incorporan mecanismos de compensación o gestión territorial en este sentido. Esta contribución se corresponde con lo que Romero (2005) llama la primera generación de políticas públicas, que permite a los municipios pequeños poder gestionar aspectos como el tratamiento de residuos o los servicios sociales. Desde este punto de vista, podemos señalar que, teniendo en cuenta el predominio de municipios de menos de 5.000 habitantes, la actuación de la mancomunidad permite a los municipios prestar servicios más allá de los mínimos que establece el art. 34 LRLCV. Sin embargo, aunque en este caso no son necesariamente los municipios más pequeños los más beneficiados, también se incorporan algunos programas innovadores de cierto potencial como los relativos al ahorro energético y la negociación conjunta con proveedores de energía. Siendo estas acciones derivadas de 
programas europeos, tal vez sí que cabría destacar como contribución del ente mancomunal la captación de recursos y de programas europeos a los que, por falta de medios, a los municipios más pequeños les sería difícil acceder (reforzando así el carácter asistencial de la mancomunidad).

Debe destacarse en este sentido el papel que juega el Consorcio de la Ribera, formado por las Mancomunidades de la Ribera Alta y de la Ribera Baixa (un nuevo ejemplo de cooperación territorial de segundo nivel). Coordina los servicios de Riberaturisme, la AER y el PATER. A través de él se articulan la mayor parte de proyectos europeos que implementa la mancomunidad, como claro ejemplo de logro de economías de escala y capacidad de influencia ('lobbying'). Una parte importante de estos proyectos se articulan mediante la AER, y están relacionados con la sostenibilidad y la eficiencia energética, tanto mediante programas de sensibilización y formación como con servicios prestados a los ayuntamientos para el ahorro mediante el aprovechamiento de economías de escala. Estos programas se complementan y enmarcan en estrategias de medio plazo, incorporando por tanto cierta componente de planificación. Un ejemplo de ello es la iniciativa del Pacto de los Alcaldes ${ }^{6}$, de la Comisión Europea, en la cual se enmarcan una serie de programas europeos coherentes con sus objetivos. También mediante el PATER se implementan proyectos europeos en la comarca. Estos proyectos, en el año 2014, estaban relacionados con: la inserción laboral de desempleados del sector de la construcción para el desarrollo de la construcción sostenible, el fomento del emprendedurismo, la inclusión de las mujeres del ámbito rural y la inclusión social de sectores excluidos (también en relación con los objetivos de la Estrategia Europa 2020).

En este tipo de proyectos, la mancomunidad permite tanto la captación de recursos y la implementación de programas avanzados a los que, de otro modo, los municipios tendrían difícil acceso, como la cooperación entre municipios y territorios de diferentes países de Europa. Ello facilita el contacto directo con realidades, experiencias y prácticas diferentes, así como la mejor toma en consideración de los principios de sostenibilidad, participación y concertación en las políticas y acción de gobierno de los

6 Mediante la adhesión a esta iniciativa los municipios se comprometen a elaborar un inventario de las emisiones del municipio y a aplicar un Plan de Acción de Energía Sostenible con el objetivo de reducir un $20 \%$ las emisiones de $\mathrm{CO}^{2}$, en línea con lo establece la Estrategia Europa 2020. Dentro de este objetivo existen, a su vez, diversos programas que contribuyen al cumplimiento de estos fines, a los cuales los municipios se pueden adherir. Posteriormente se revisó y se plantearon unos nuevos objetivos de cara al 2030, pasando a denominarse "Pacto por el Clima y la Energía" 
municipios. Los proyectos europeos requieren normalmente la articulación de diversas estructuras de gobernanza, y de la participación tanto en la gestión como en la implementación de los programas. Ello facilita el desarrollo de nuevos modelos de gobernanza vía mancomunidad: consejos consultivos con presencia de los actores locales, colaboración e intercambio de experiencias entre municipios y actores, estrategias participativas para la elaboración de Planes de Acción, o la cooperación entre municipios, empresas y universidades. De este modo, mediante los fondos europeos que capta la mancomunidad, se están desarrollando estructuras de participación y consenso que tratan de incorporar un enfoque estratégico, adaptándose a la propia realidad territorial. Una nueva forma de poder afrontar la falta de modelos territorializados de gobernanza propios que, desde el conocimiento de las necesidades de la comarca, incorporen estrategias participadas para la cohesión y la equidad territorial.

\section{ConClusiones}

La gobernanza es un elemento importante en la búsqueda de una mayor cohesión territorial en nuestras sociedades y también para la creación de las condiciones que permitan una mayor equidad territorial. Así, la cooperación y colaboraciónsonelementosdegestiónterritorialfundamentalesparaundesarrollo más equilibrado, y como tal quedan recogidos en los documentos oficiales sobre la materia. Sin embargo, en nuestro contexto, el territorio valenciano, la regla general es que la cooperación, en lo referente a las mancomunidades, presente fundamentalmente un carácter meramente interadministrativo y que su funcionamiento se corresponda con las tradicionales formas de gobierno, quedando lejos todavía las fórmulas de gestión territorial y de gobernanza de carácter más relacional, estratégica y proactiva.

El caso de MANRA es una muestra más de este modelo. En primer lugar, no existen instrumentos específicos de equidad y compensación territorial. Tampoco existe una planificación estratégica integrada (bajo la forma de plan estratégico, de inversión territorial integrada o de estrategias de desarrollo local participativo) que contemple fórmulas flexibles y relacionales de cooperación, y que desde las potencialidades del territorio se proponga como objetivo una mayor equidad y cohesión social.

Aun con todo, la cooperación intermunicipal, en su funcionamiento ordinario y limitado a la prestación de servicios, coadyuva de forma relevante a un mayor acceso a los mismos por parte de los municipios pequeños, 
contribuyendo así en elementos tangibles y concretos a una mayor equidad territorial. Teniendo en cuenta que la mayor parte de municipios de la comarca tienen menos de 5.000 habitantes, las economías de escala generadas por la propia cooperación permite a estos municipios facilitar el acceso de sus ciudadanos a servicios más allá de los que la ley les obliga a prestar, y que de otro modo no les sería posible. Por tanto, en este caso, a falta de instrumentos concretos para paliar las desiguales condiciones y características de los municipios, es la generación de economías de escala el elemento favorecedor del acceso a los servicios.

Esta contribución de la mancomunidad a la igualdad de acceso a los servicios por los municipios tiene lugar principalmente en materias «clásicas» de cooperación municipal, siendo el tratamiento de residuos el ejemplo paradigmático. No obstante, también es cierto que el catálogo de servicios es relativamente amplio y que llegan a ser, en función de los municipios, bastante diversos también los servicios a los que los municipios se adhieren (por ejemplo la asistencia en relación con el tráfico o los diferentes tipos de servicios sociales). Además, la MANRA está facilitando a todos los municipios la posibilidad de acceder a servicios generales como la agencia de desarrollo comarcal, la agencia para la promoción de la diversidad y, de forma destacada, el acceso a programas europeos en diferentes materias. Ejemplos de programas europeos aplicados en los municipios vía mancomunidad son algunos servicios que presta la AER en materia de optimización energética y sostenibilidad, los cuales, además, incluyen en ocasiones algunos elementos de innovación y gobernanza asociados a proyectos y financiación comunitaria a partir del Consorcio de La Ribera, un ejemplo de cooperación territorial que podemos denominar de segundo grado.

En todo caso, y en lo relativo al tipo de servicios solicitados, se observan diferencias relevantes entre los municipios de la comarca en función de su volumen demográfico. Las diferencias son especialmente sensibles en los tres municipios de más de 20.000 habitantes, donde los servicios relacionados con la movilidad y sostenibilidad urbana cobran una mayor relevancia. Mientras que los municipios con menor población se adhieren a servicios de carácter más básico, los mayores lo hacen a servicios más especializados, aunque si nos referimos a los servicios opcionales, esta adhesión no difiere sustancialmente entre los municipios por debajo de 20.000 habitantes (un umbral que se muestra determinante).

Dadas estas diferencias, y tal como se recoge tanto en algunos documentos oficiales como en la práctica, un modelo de desarrollo equilibrado basado en la complementariedad urbano-rural debe contemplar mecanismos de 
compensación y estructuras flexibles de gobernanza que posibiliten que los municipios del entorno pueda acceder a la actividad económica, los servicios y la innovación mediante las ciudades intermedias. El predominio de una cultura y tradición más asistencial y clientelar que proactiva y propositiva, capaz de promover innovación social e iniciativas autóctonas que apunte, por qué no, a nuevas formas de desarrollo alternativas o complementarias del actual modelo (que justamente contribuye a explicar este comportamiento), sigue siendo un reto, ambicioso a tenor de lo que demuestra la experiencia y hemos comprobado en este trabajo, a pesar del interesante y positivo influjo de los programas europeos. Decisión política para redoblar esfuerzos en este sentido se nos antoja crucial, en estos momentos, para tratar de entrar en mejor sintonía, precisamente, con los instrumentos de la nueva política de cohesión europea, con especial atención a las inversiones territoriales integradas y a las estrategias de desarrollo local participativo.

\section{Agradecimientos}

Este trabajo ha sido realizado en el marco del proyecto de investigación CSO2012-36960 «Del gobierno a la gobernanza y gobernabilidad efectiva del territorio: guías para un nuevo desarrollo territorial», Plan Nacional de I+D+i 2008-2011, cofinanciado por el FEDER.

\section{BiBLIOGRAFÍA}

Alesina, A. y Spolaore, E. (2008): La mida de les nacions, Lid Editorial, Barcelona.

Barca, F. (2009): An Agenda for a Reformed Cohesion Policy. A place-based approach to meeting European Union challenges and expectations. Independent Report prepared at the request of Danuta Hübner, Commissioner for Regional Policy. 244 pp. Disponible en: http://ec.europa.eu/regional_policy/archive/policy/future/pdf/ report_barca_v0306.pdf. Consultado: 20/08/2015

Barreiro, C. (2005): "Fórmulas asociativas de prestación de servicios supramunicipales: la comarca, mancomunidades de municipios y consorcios", Revista de estudios locales. Cunal, no 81, 56-69.

Bel, G. y Warner, M.E. (2013), "Factors explaining inter-municipal cooperation in service delivery: a meta-regression analysis", Public Managements Research Association Conference.

Comisión Europea (2001): La Gobernanza europea. Un libro blanco, COM (2001) 428 final, Bruselas. Disponible en: http://eur-lex.europa.eu/legal-content/ES/TXT/PDF/ ?uri=CELEX:52001DC0428\&from=ES. Consultado: 08/08/2015 
Comisión Europea (1999), Estrategia Territorial Europea. Hacia un desarrollo equilibrado y sostenible del territorio de la UE, Bruselas. Disponible en: http://ec.europa.eu/ regional_policy/sources/docoffic/official/reports/pdf/sum_es.pdf Consultado: $10 / 08 / 15$

Comisión Europea (2004). Tercer informe sobre la cohesión económica y social. Oficina de Publicaciones Oficiales de las Comunidades Europeas, Luxemburgo Disponible en: http://ec.europa.eu/regional_policy/sources/docoffic/official/reports/pdf/ cohesion3/cohesion3_toc_es.pdf Consultado: 25/08/2015

Comisión Europea (2008). Libro Verde sobre la cohesión territorial. Convertir la diversidad territorial en un punto fuerte. COM (2008) 616 final, Bruselas. Disponible en: http://ec.europa.eu/regional_policy/archive/consultation/terco/paper_terco_es.pdf Consultado: 10/08/2015

Comisión Europea (2010), Europa 2020. Una estrategia para un crecimiento inteligente, sostenible e integrador, COM (2010) 2020 final, Bruselas. Disponible en: http:// eur-lex.europa.eu/LexUriServ/LexUriServ.do?uri=COM:2010:2020:FIN:ES:PDF Consultado: 13/08/2015

Conselleria de Medi Ambient, Aigua, Urbanisme i Habitatge (2011a), "Objetivo 1: Sistema de ciudades: mantener la diversidad y la vertebración del sistema de ciudades", Estrategia Territorial de la Comunitat Valenciana, vol. 3, Generalitat Valenciana. Disponible en: http://www.citma.gva.es/estatico/areas/estrategia_territorial/03/ html/index.html Consultado: 19/08/2015

Conselleria de Medi Ambient, Aigua, Urbanisme i Habitatge (2011b), "Objetivo 12: Gestión Territorial: aplicar de forma eficiente los instrumentos de equidad territorial", Estrategia Territorial de la Comunitat Valenciana, vol. 14, Generalitat Valenciana. Disponible en: http://www.citma.gva.es/estatico/areas/estrategia territorial/14/html/index.html Consultado: 20/08/2015

Conselleria de Medi Ambient, Aigua, Urbanisme i Habitatge (2011c), "Objetivo 25: Gobernanza Territorial: desarrollar fórmulas innovadoras de gobernanza territorial”, Estrategia Territorial de la Comunitat Valenciana, vol. 27, Generalitat Valenciana. Disponible en: http://www.citma.gva.es/estatico/areas/estrategia_territorial/27/ html/index.html Consultado: 20/08/2015

Conselleria de Medi Ambient, Aigua, Urbanisme i Habitatge (2011d), "Áreas funcionales: els Ports-Baix Maestrat, Castellón, el Valle del Palancia, Valencia, Requena-Utiel, la Ribera del Xúquer, Xàtiva, la Safor, la Vall d'Albaida, la Marina Alta, Alcoi, la Marina Baixa, el Vinalopó, Alicante-Elx, la Vega Baja", Estrategia Territorial de la Comunitat Valenciana, vol. 29, Generalitat Valenciana. Disponible en: http://www. citma.gva.es/estatico/areas/estrategia_territorial/29/html/index.html. Consultado: 20/08/2015

D’Anjou, J. (1994), Las Mancomunidades Intermunicipales en el Régimen Local Español, Ministerio para las Administraciones Públicas

FALUdi, A. (2005), "La política de cohesión territorial de la Unión europea", Boletín de la Asociación de Geógrafos Españoles, n 39, 11-30. 
FARINós, J. (2008); "Gobernanza territorial para el desarrollo sostenible: estado de la cuestión y agenda”, Boletín de la Asociación de Geógrafos Españoles, nº 46, 11-32.

FARINós, J. (2009): "Cooperación para la cohesión territorial: Una interpretación multinivel desde el SO Europeo", en Bosque, J., Rodríguez, V.M. (eds.) La perspectiva geográfica ante los retos de la sociedad y el medio ambiente en el contexto ibérico, Servicio de Publicaciones de la Universidad de Alcalá de Henares, Alcalá de Henares. Colección Ponencias del XI Coloquio Ibérico de Geografía, (117-148).

FARINós, J. (2013): "Territorial Cooperation as a Means of Achieving Territorial Integration? From Local Place-based to European Union Territorial Cohesion”, en Gorzelak, G. \& K. Zawalińska, K. (eds.). European Territories: From Co-operation to Integration. ESPON \& EUROREG - Centre for European Regional and Local Studies, University of Warsaw, Varsovia, 42-53. Diponible en: http://www.euroreg. uw.edu.pl/dane/web_euroreg_publications_files/3171/gorzelak_2013_european_ territories.pdf. Consultado: 22/08/2015

FARINós, J. y PAYÀ (2006): "La experiencia de las Comarcas Centrales", en Romero, J. y Farinós, J. (coords.) Gobernanza territorial en España: claroscuros de un proceso a partir del estudio de casos, IIDL-PUV, Colección 'Desarrollo Territorial' n ${ }^{\circ} 1$, Valencia, (193-218).

Fernández Tabales, A., Pedregal, B., Rodríguez Mateos, J.C., Pita, M.F. y Zoido, F. (2009): "El concepto de cohesión territorial. Escalas de aplicación, sistemas de medición y políticas derivadas", Boletín de la Asociación de Geógrafos Españoles, no 50, 157-172.

Font, T. y Perdigó, J. (2002): "Las nuevas fórmulas institucionales para la equidad territorial y la cooperación municipal", Anuario del Gobierno Local, 99-108.

Lago-Peñas, S. y Martínez Vázquez, J. (ed.) (2013): The challenge of local government size, Edwar Elgar.

Lois, R.C., Feal, A.M, y Paül, V. (2013): "La dimensión territorial de la Estrategia Europa 2020. Las regiones europeas en la senda oficial para salir de la crisis", Ería, $n^{\circ}$ 93, 211-242.

Mancomunitat de la Ribera Alta (2015): Memòria anual d'activitats 2014, Alzira.

Membrado, J.C. (2013): "La diversidad territorial valenciana: antecedentes, problemas y política de la Generalitat", Investigaciones Geográficas, no 59, 5-24.

Méndez, R. (2006), "Del Distrito Industrial al Desarrollo Territorial: estrategias de innovación en ciudades intermedias", Desenvolvimento em questao, año 4, no 7, 9-46.

Ministerio de Medio Ambiente y Medio Rural y Marino - MMARM- (2009): "Población y Sociedad Rural”. Análisis y Prospectiva-Serie AgrInfo, n 12. Subdirección General de Análisis, Prospectiva y Coordinación, Subsecretaría. MMARM.

Ministerio de Política Territorial - MPT- (2009): "Las entidades locales en la Comunitat Valenciana", Subdirección General de Estudios y Sistemas de Información Local, Secretaría General Técnica, MPT, Madrid. Disponible en: http://www.seap. minhap.es/dms/es/areas/politica_local/sistema_de_informacion_local_-SIL-/registro_eell/estudios/estudios_ccaa/parrafo/011/LASENTIDADESLOCALESENLACOMUNI TATVALENCIANA.pdf. Consultado: 17/08/2015 
OdTA (Observatorio sobre la Cohesión, Diversidad y Desarrollo Territorial de Andalucía) (2009): Libro Verde sobre la Cohesión Territorial. Aportaciones del Foro de expertos sobre la cohesión, la diversidad y el desarrollo territorial. Reflexiones en torno al Libro Verde de la Comisión de las Comunidades Europeas. Disponible en: http:// www.upo.es/ghf/giest/ODTA/documentos/Foro/LIBRO_VERDE_RESPUESTASODTA_final.pdf. Consultado: 15/08/2015

Ojeda, S. (2008): Equidad Territorial en Andalucía, Sevilla, Instituto de Estadística de Andalucía.

Pascual, H. y García Cuesta, J.L. (2008), "Políticas urbanas para el desarrollo y la innovación en las ciudades intermedias", Investigaciones geográficas, n 47, 5-25.

Pillet, F., Cañizares, M.C., Ruiz, A.R., Martínez, H.S., Plaza. J., y Santos, J.F. (2013), "Los indicadores de la cohesión territorial en el análisis de la escala supramunicipal o subregional: policentrismo y áreas funcionales (FUAS)", ERÍA, 90, 91-106.

Precedo, A. (2006): "Cooperación intermunicipal e identidad territorial en espacios rurales: el futuro de la comarca", Urban Public Economics Review, nº 6, 113-149.

Riera, P.; Amer, C., Vilaplana, V. y Haas, C. (2015): "Las mancomunidades en España", Boletín de la Asociación de Geógrafos Españoles, n 39, 151-176.

Romero, J. (2005), "El gobierno del territorio en España. Balance de iniciativas de coordinación y cooperación territorial", Boletín de la Asociación de Geógrafos Españoles, no 39, 59-86.

Salom, J. (2010), "Procesos territoriales y transformaciones recientes del sistema urbano valenciano", Scripta Nova, vol. XV, nº 356.

Fecha de recepción: 2 de noviembre de 2015.

Fecha de aceptación: 17 de marzo de 2016. 